\title{
AN ANALYSIS OF METHODS FOR DERIVING MAGNITUDES OF HISTORIC EARTHQUAKES THAT ARE BASED ON PHYSICAL PRINCIPLES
}

\author{
Christopher S. Belsham \\ Office for Nuclear Regulation \\ Redgrave Court, Merton Road, Bootle, Merseyside, L20 7HS, United Kingdom \\ c_belsham@o2.co.uk
}

Key words: Macroseismic Intensity; Stable Continental Regions; Historical seismicity; Stochastic Method; spectral ground acceleration; attenuation quality factor.

\begin{abstract}
A large proportion of the land mass of the world is classified as Stable Continental Regions, these are generally regions where the seismic activity is low. Consequently there is little instrumentally recorded strong-motion data available from which to build robust models for seismic hazard evaluation for these regions. Recourse is therefore made to using spatial events as a surrogate for temporal events, on the assumption that the regions selected spatially have similar tectonic characteristics. Even this approach requires the addition to the database of historic events, these are events that have been recorded pre-instrumentally using macroseismic intensity records as the basis. This leads to a key objective of the analysis of historic seismic data is the determination of a relationship between an events macroseismic intensity records and its magnitude through regression analysis of a large set of known data.

An important part of regression analysis for this type of data is the development of a functional form that matches the nature of the data and models the physical processes that gives rise to it. The equations which are considered and compared in this paper are those of Frankel, Johnston, Ambraseys, Murphy and O'Brien and Kövesligethy. In addition, to explain how these equations relate to the physical process, Frankel's equation is compared with the equation from Boore's Stochastic Method.

The paper then compares, in detail, the magnitude-intensity relationships developed by Johnston and Ambraseys, the interest focusing on the different regression techniques used. This is followed by an exploration of the merits of each approach with the analysis using Johnston's global dataset of Stable Continental Region events. The discussion between these models provides the basis for the development of a typical value for the attenuation quality factor $Q$ for Stable Continental Regions in the frequency range 1 to $5 \mathrm{~Hz}$. Together the findings in this paper provide the opportunity for developing ground motion prediction equations from a mixed macroseismic and instrumented approach. It also provides a means to further improve the knowledge of macroseismic data and notes potential uncertainties in the values of the derived magnitudes.
\end{abstract}




\section{INTRODUCTION}

The advantage of being able to enlarge the earthquake database in regions of low seismic activity using historic earthquakes has been understood for several decades and a number of major studies have been carried out to derive the magnitudes for historic earthquakes. Two studies in particular stand out because they consider large regions using geological rather than political boundaries to define the scope of the data considered. In addition they are developed from underlying physical principles and therefore satisfy the conclusions in NERIES [1]. The first of these studies was carried out by Ambraseys [2] and considered the Intraplate region of North Western Europe (NWE). The second study was by Johnston [3] which considered data collected from regions worldwide that satisfied the criteria that defined them as Stable Continental Regions (SCR). The term SCR was introduced in Johnston [4], prior to which tectonic regions were classified as either interplate or intraplate. Johnston identified nine SCRs; Africa, East Antarctica, North America, South America, Europe, Asia, India, China, Australia. NWE forms a subset of the European Stable Continental Region. The remaining regions of the world are termed Non Stable Continental Regions (NSCR).

Johnston and Ambraseys used different types of regression analysis and functional forms but the underlying principle is the same. The method relies on selecting a range of earthquakes for which there are both instrumented and macroseismic intensity data available thus giving both the magnitude and the isoseismals. Then a regression analysis is performed to determine the values of the coefficients in the functional equation or a set of functional equations. The functional equations with assigned values for the coefficients, derived from the regression, relate the magnitude of an event to the macroseismic intensity data. The equation(s) can then be used to find the magnitudes for those cases where macroseismic intensity records are the only data available.

The Johnston [3] study recognised that in order to construct a large database for SCRs it is necessary to extend the spatial region to compensate for the lack of temporal data in a particular region. This required that a global view be adopted and involves an underlying assumption that all SCRs are fundamentally the same. In contrast the Ambraseys [2] dataset is for the much smaller region of NWE. On the basis that the larger of the two dataset is Johnston's, it has been selected for use in exploring the methodologies developed by Johnston and Ambraseys and to compare the two approaches. An important measure of the robustness of these types of methods is how well they recreate the input dataset; this test is applied to both methods.

The database presented in Johnston [3] has multiple entries for many of the events. For this study, the entry that contains the highest number of isoseismal radii are selected. The resulting dataset used in this study is given in Appendix A.

Validation of complex models such as those considered in this study is very difficult. It might at first appear that testing with an independent event would be a strong test; however, because the regressions have a large uncertainty such a test is in fact only weak. In cases such as this it is preferable to rely on how well the methodologies match the physical process and the quality of the data used. The physical process is considered to be adequately represented by the equation presented in the Stochastic Method, Boore [5].

\section{METHODS USED TO DERIVE EVENT MAGNITUDES FROM INTENSITIES}

Many equations have been developed for the study of macroseismic intensity; in this paper those by Frankel [6] as used by Johnston [3], Ambraseys [2], Murphy and O'Brien [7] and Kövesligethy [8] are considered. The study of these equations and their parameters shows 
there is a close relationship between them and it is also shown that they are closely related to the source to site model that forms the basis of the Stochastic Method, Boore [5].

A notable difference between the approach of Johnston and Ambraseys is that the parameters $m$ and $n$ are free to vary with intensity in Johnston's method but are constrained to a single value in Ambraseys method. This is particularly important for the determination of the value of $Q$. Johnston recognised the significance of the spectral response frequency but did not have sufficient information to refine the values beyond blocks of $3 \mathrm{~Hz}$ and $5 \mathrm{~Hz}$. Belsham [9] determined the frequencies that are characteristic of each intensity level through dynamic analysis of the intensity indicators. Those values are used in this paper to assign specific response frequencies to each intensity level between II and VIII. With this new information an alternative study of $Q$ is possible.

In this article the terms macroseismic intensity is used interchangeably with intensity and both Roman and Arabic numerals are used to define intensity levels. MSK and MMI scales are used interchangeably based on the comparison in Murphy and O'Brien [7].

\section{JOHNSTON'S APPROACH}

Johnston bases his analysis on an equation developed by Frankel [6], which has the form shown by equation (1)

$$
A=A_{0} r^{-n} e^{-m r}
$$

where $n$ is a geometric spreading factor and $m$ is a coefficient of attenuation. Starting by taking the log of equation (1) results in equation (2)

$$
\log A=\log A_{0}-n \log r-0.435 m r+c
$$

where $c$ is a constant. For a given isoseismal, with an equivalent circular felt area $S$, the radius is $r=(S / \pi)^{1 / 2}$ and as $\log A$ is a constant for each felt area equation (2) therefore reduces to equation (3)

$$
\log A_{0}=0.5 n \log (S / \pi)-0.435 m \sqrt{S / \pi}+c
$$

To finish relating the moment magnitude $M_{w}$ to the felt area $S$, the Fourier amplitude $A_{0}$ needs to be found in terms of $M_{w}$. From the seismic moment $M_{0}$ Boore [5] derives the relationship shown in equation (4)

$$
\log A_{0}=\frac{1}{3} \log M_{0}+C
$$

Frankel then uses equation (5) from Hanks and Kanamori [10]

$$
\log M_{0}=1.5 M_{w}+16.0
$$

and substitutes it into equation (4) to give equation (6)

$$
\log A_{0}=0.5 M_{w}+C
$$

then substituting equation (6) into equation (3) produces equation (7)

$$
M_{w}=n \log (S / \pi)+0.87 m \sqrt{S / \pi}+c
$$

where $n$ and $m$ are factors to be determined from the regression analysis of the data. As the Johnston [3] data values differ from those used by Frankel [6], A new analysis of Johnston's 
data has been carried out. Using intensity level II shows that the example in Frankel [6] is compatible with the data from Johnston [3] with the revised results shown in Figure 1. A visual comparison with figure 1 in Frankel's paper indicates that any changes are very small.

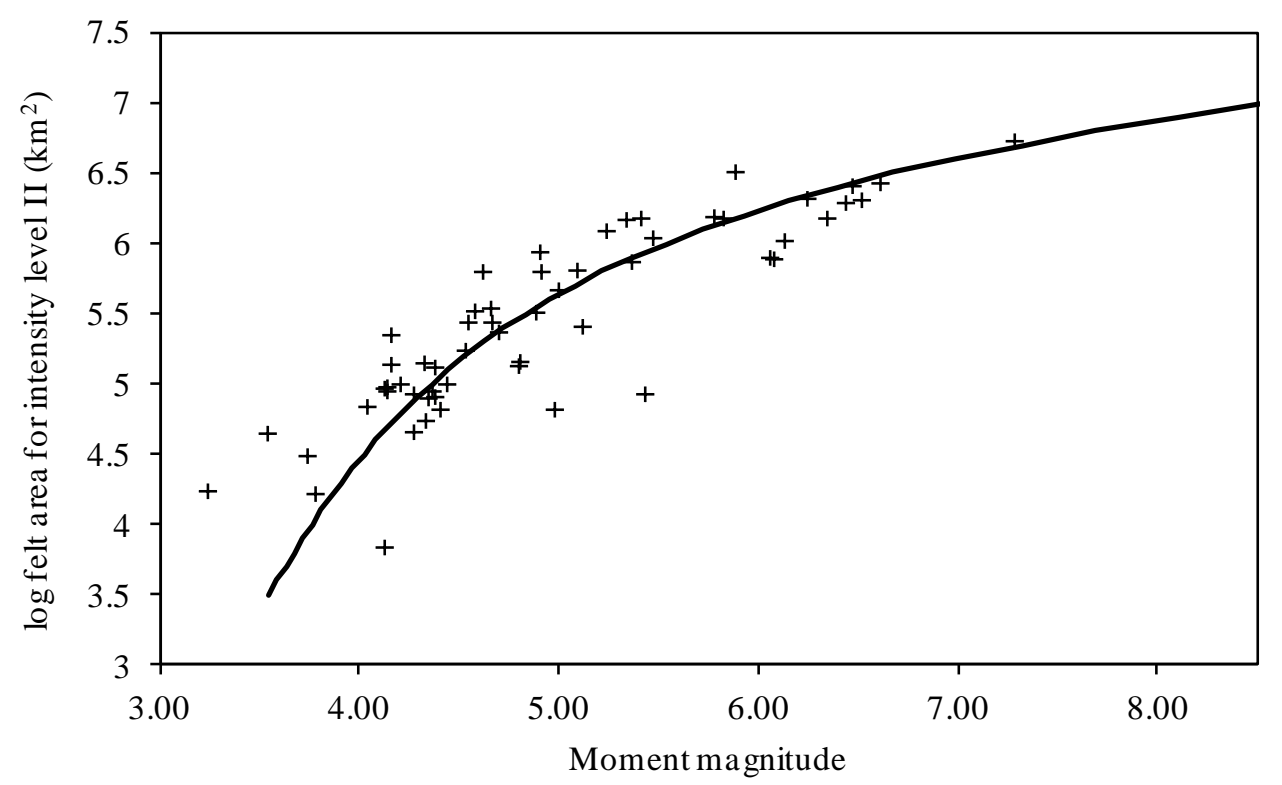

Figure 1 Plot showing that Frankel's functional form is compatible with Johnston's revised data

\section{AMBRASEY'S APPROACH}

The equation developed by Ambraseys [2] uses the equation for energy decay from a point source which is given by equation (8)

$$
E=\frac{E_{S}}{4 \pi r^{n}} \exp (-m r)
$$

where $E$ is the energy density at a distance $r$ from the point source and $n$ and $m$ represent the same parameters as in equation (1) and $E_{S}$ is the source energy given by equation (9)

$$
\log \left(E_{S}\right)=\varphi+\theta M_{S}
$$

where $\varphi$ and $\theta$ are constants and $M_{S}$ is the surface wave magnitude. According to Ambraseys [2] the constants are approximately $\varphi=12.0$ and $\theta=1.50$. Referring to equation (1), equation (8) is its equivalent in terms of energy. Using equations (8) and (9) in conjunction with other equations Ambraseys [2] derived equation (10)

$$
M_{S}=c_{1} I+c_{2} \log r+c_{3} r+c_{0}
$$

where $c_{2}=n / \theta$ and $c_{3}=0.43 \mathrm{~m} / \theta$, which for a typical value for $\theta=1.5$ gives $c_{2}=0.67 n$ and $c_{3}=0.29 \mathrm{~m}$. The regression analysis determines the coefficients $c$ from which the values for $m$ and $n$ can be found.

Murphy and O'Brien [7] found that the peak ground acceleration $a$ in terms of intensity $I$ is given by equation (11)

$$
\log a=b_{1} I+b_{0}
$$

where $b_{0}$ and $b_{1}$ are constants depending on the region. For the global case, with $a$ in units of $\mathrm{m} / \mathrm{s}^{2}$ they are 0.25 and -1.75 respectively. Substituting equation (11) into equation (10) and gathering $b_{0}$ into $c_{0}$ and adjusting $c_{1}$ results in equation (12) 


$$
M_{S}=c_{1} \log a+c_{2} \log r+c_{3} r+c_{0}
$$

In equation (12) $\log a$ is constant and for a given felt area can be combined into $c_{0}$. Then setting $c_{2}=n, c_{3}=0.87 m$ and $c_{0}=C$ gives equation (7) and shows that Frankel's approach is the same basic formulation as that of Ambraseys.

As shown by Ambraseys [2] equation (12) can be developed from an equation formulated by Kovesligethy [8], which is equation (13)

$$
I=a_{1} \log (E)+a_{0}
$$

where $E$ is the energy and the $a$ 's are constants to be determined from the data, it therefore follows that equation (1) is related to equation (13). In passing, the similarity between equations (11) and (13) is noted.

\section{COMPARISON OF FRANKEL'S MODEL WITH THE POINT SOURCE MODEL}

This section will show that equation (1) used by Frankel [6] is equivalent to a source model approach where the Fourier amplitude spectra is found from a source term multiplied by a path term. Boore [5], [11] has developed the point source model into the Stochastic Method, to the point where it is generally accepted as a robust analysis approach. The principle equation has the form shown in equation (14)

$$
A(f, r)=A_{0} Z(r) D(f, r) S(f)
$$

where $A_{0}$ is the Fourier Amplitude of the seismic source at depth, $Z(r)$ is the dispersion term or spreading function, $D(f, r)$ is the attenuation term and $S(f)$ is the site response term, the combined terms giving the Fourier Amplitude $A(f, r)$ at the surface for frequency $f$ at epicentral distance $r$. The source model therefore derives the Fourier acceleration at the rupture and then determines what the Fourier acceleration is at the surface at a given distance from the source taking into account the attenuation and spreading with distance.

In Frankel's model the site term is not present. Frankel's model therefore consists of a Fourier acceleration $A_{0}$ at the source below the epicentre, a dispersion term for the distance $r$ from the source, which for the far-field considered by Frankel is given by $r^{-n}$ and an attenuation term $\exp (-(\pi f / Q \beta) r)$, where $f$ is the frequency, $Q$ is the quality factor and $\beta$ is the shear wave velocity in the basement rock. Frankel equates $\pi f / Q \beta$ to $m$. It is therefore seen that Frankel's equation (1) is a form of point source model, which from Boore [11] has the form shown in equation (15)

$$
a=\frac{V R_{\theta} F M_{0}}{4 \pi \rho \beta^{3}} \frac{(2 \pi f)^{2}}{1+\left(f / f_{0}\right)^{2}} Z(r) \exp \left(-\frac{\pi f}{\beta Q} r\right)
$$

here $A_{0}$ is given by equation (16), which is the first two terms in equation (15)

$$
A_{0}=\frac{V R_{\theta} F M_{0}}{4 \pi \rho \beta^{3}} \frac{(2 \pi f)^{2}}{1+\left(f / f_{0}\right)^{2}}
$$

where $M_{0}$ is the seismic moment, $\rho$ is the density of the basement rock, $V$ is the component factor normally $1 / \sqrt{2}, R_{\theta}$ is the source radiation factor with a typical value of 0.55 and $F$ is the surface reflection factor, $f_{0}$ is the corner frequency and $f$ is the frequency at which $a$ is 
required. The geometrical spreading term $Z(r)$ equates to $r^{-n}$ in Frankel's equation and the last term, the attenuation, is the same in both cases. This shows the equivalence of Frankel's approach and the point source model.

\section{COMPARISON OF REGRESSION METHODS USED TO DERIVE EARTHQUAKE MAGNITUDES FROM MACROSEISMIC INTENSITIES}

Studies to derive earthquake magnitudes from macroseismic intensities from historic events are a major undertaking and as a consequence there are not a large number of such studies; of those that have been carried out, two stand out. These are the studies discussed above, namely, Ambraseys [2] and Johnston [3]. Although the fundamental philosophy is the same in each of these studies, the details are different. It is important for future studies in this subject to understand the differences between the two approaches and if possible draw a conclusion as to which approach gives the more representative results. This later requirement introduces the need to find a means of measuring the results of the analyses.

\subsection{The data}

The database used in this study is tabulated in Appendix A and is presented graphically in figures 2 and 3. It has been divided into two graphs because of the density of the data and by plotting every other intensity level in each figure it provides improved clarity.

During the processing of the regression analysis it was found that using just Table A.1. data resulted in a poor fit for intensity level VI data and an extremely poor fit for intensity level VII and VIII data. A first step in improving the regression was to include the data from Table A.2. in Appendix A. This made improvements to those intensity levels but the shape of

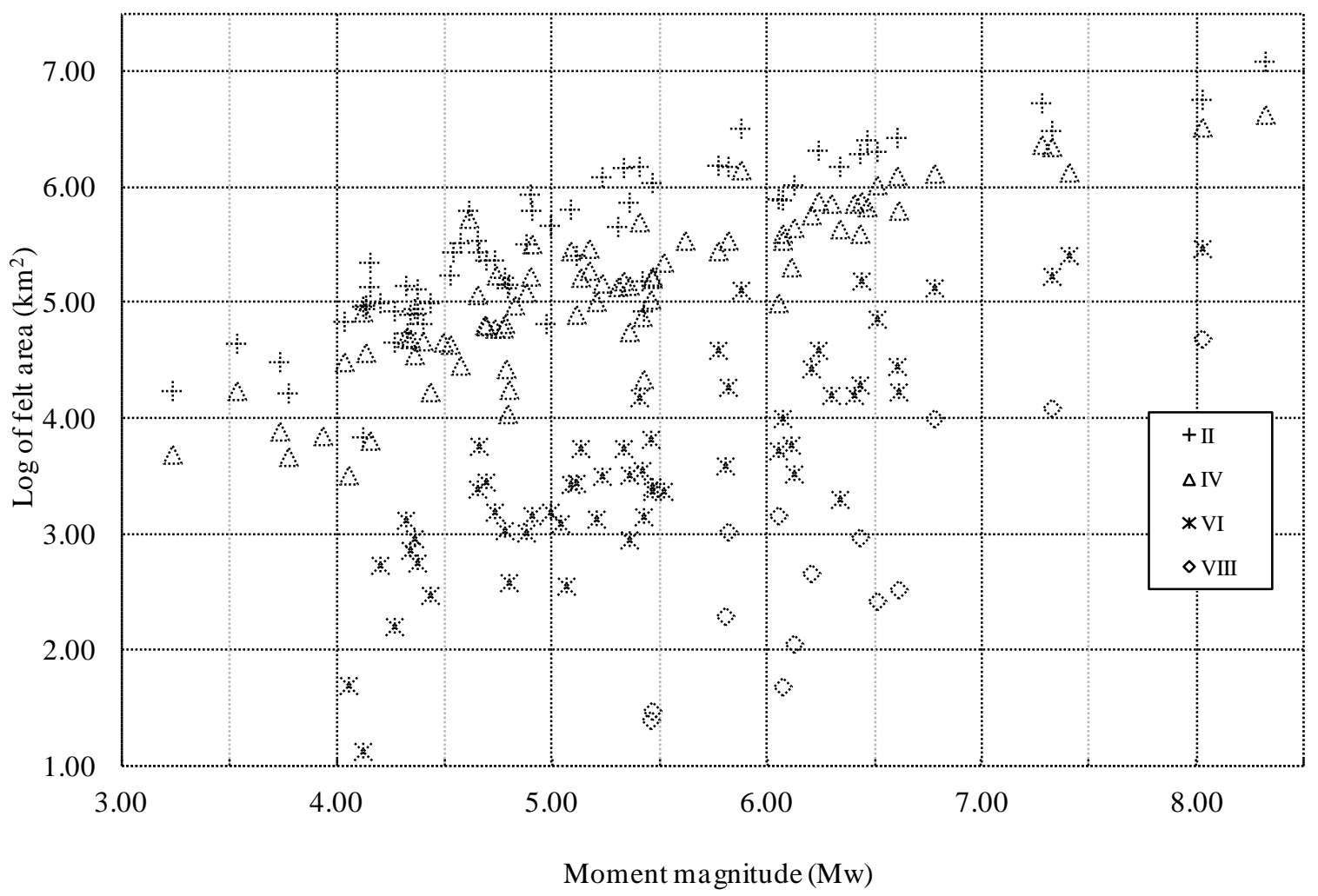

Figure 2. Data points from the database in Appendix A for intensity levels II, IV, VI and VIII 


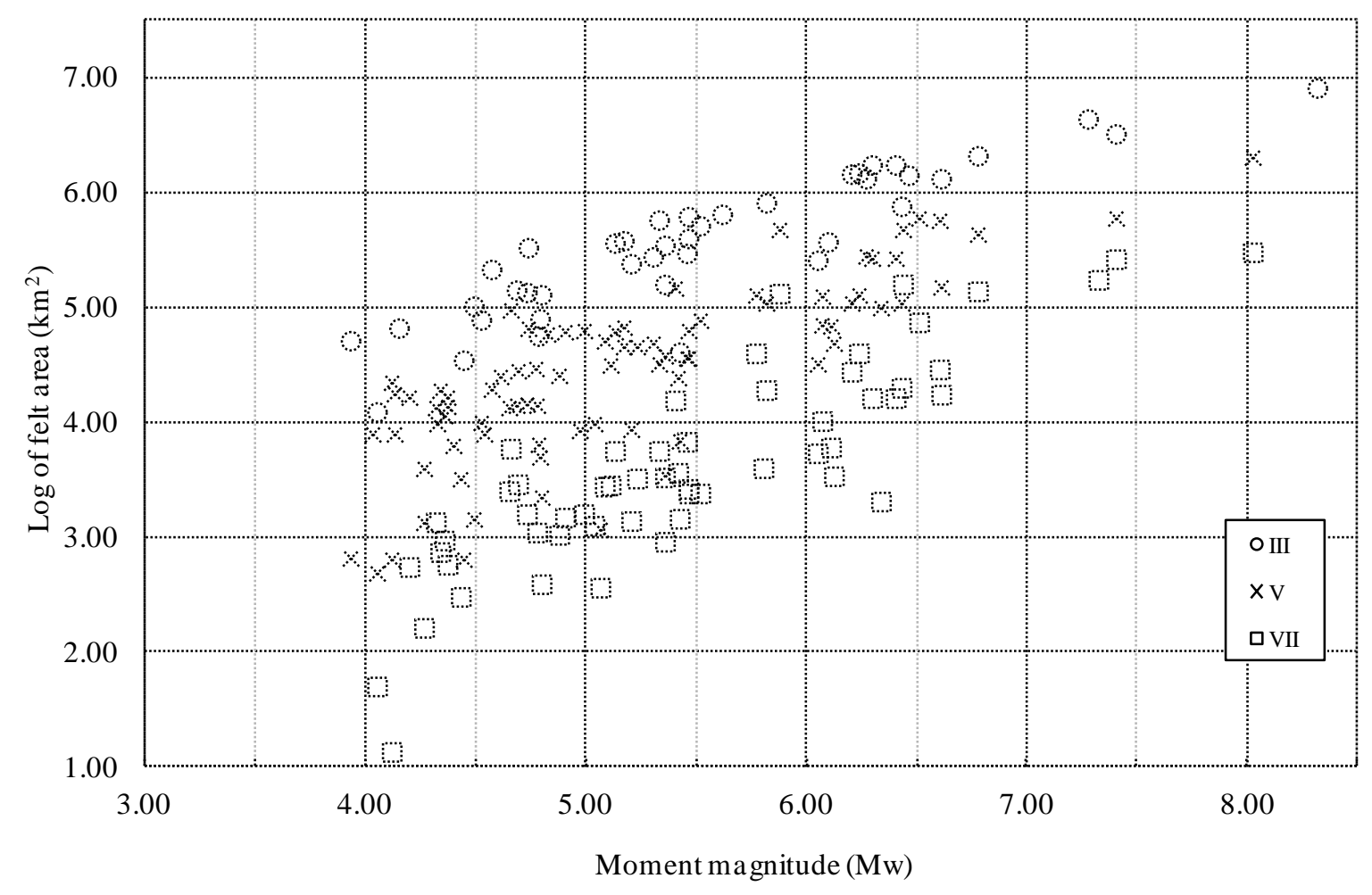

Figure 3. Data points from the database in Appendix A for intensity levels III, V, VII

the intensity level VI curve remained at variance with the other intensity curves. Investigation of the database for intensity VI using trial adjustments revealed that the entry from the Bihar, India 1934 event was constraining the regression curve. Inspection of the data entry showed it to have a large associated uncertainty and examination of the plot of the isoseismal included in Johnston [3] showed an elongated shape. Further evidence for this is found in [12] where Kriging has been used to determine the isoseismals, which is shown in figure 4(j) in that paper. Although the isoseismal radii are not given in the report, simple scaling from the plot gives $r_{\mathrm{VI}}$ of $0.3 \mathrm{e} 6$. This shows that the intensity level VI area $A_{\mathrm{VI}}$ can be significantly reduced from $1.2 \mathrm{e} 6$ to $0.3 \mathrm{e} 6$, giving $\log \left(A_{\mathrm{VI}}\right)=5.48$. This then requires that the intensity level VII area $A_{\mathrm{VII}}$ is also reduced from $0.316 \mathrm{e} 6$ to $0.1 \mathrm{e} 6$, giving $\log \left(A_{\mathrm{VI}}\right)=5.00$. Including these revised isoseismal area reductions in the regression analysis results in values for the attenuation quality factor $Q$ which are consistent with the other intensity levels. These reduced values have therefore been assessed as being the more appropriate.

\subsection{Johnston's method - individual regression of each intensity level}

Johnston [3] based his analysis on equation (7). In this section the key elements of Johnston's approach are set down and then applied to the Johnston dataset, which consists of worldwide SCR events covering moment magnitudes 3.2 to 7.25. In his part II paper Johnston [3] notes that he chose not to follow Ambraseys' approach but instead uses equation (7) for each individual intensity level in the form shown by equation (17)

$$
M_{0 i}=10^{k_{0}+k_{1} \log \left(S_{i}\right)+k_{2} \sqrt{S_{i}}}
$$

Where $M_{0 i}$ is the seismic moment and $S_{i}$ is the felt area for the contributing intensity level $i$ with $k_{0}, k_{1}$ and $k_{2}$ coefficients whose values are given in Table 1 . 


\begin{tabular}{cccc}
\hline $\begin{array}{c}\text { Intensity } \\
\text { level } i\end{array}$ & $k_{1}$ & $k_{2}$ & $k_{0}$ \\
\hline 2 & 0.959 & 0.00126 & 17.31 \\
3 & 1.020 & 0.00139 & 17.59 \\
4 & 0.971 & 0.00194 & 18.10 \\
5 & 0.788 & 0.00260 & 19.83 \\
6 & 1.032 & 0.00176 & 20.23 \\
7 & 0.559 & 0.00328 & 23.22 \\
8 & 0.440 & 0.00586 & 24.05 \\
\hline
\end{tabular}

Table 1. Coefficients in Johnston's equations from Johnston [3]

Alternatively equation (17) can be written in the form shown in equation (18) which is the same as equation (7)

$$
M_{w}^{i}=n \log (S / \pi)+0.87 m \sqrt{S / \pi}+c
$$

where $n, m$ and $c$ are constants for intensity level $i$ to be determined from a regression analysis for each intensity level and are related to the coefficients with $k_{0}, k_{1}$ and $k_{2}$ by the equations (19), (20), (21) and (22).

$$
\begin{gathered}
c=0.667 k_{0}+0.497 n-10.7 \\
n=0.667 k_{1} \\
m=1.361 k_{2} \\
m=(\pi / 3.5)(f / Q)=0.898(f / Q)
\end{gathered}
$$

where $f$ is frequency and $Q$ is a regional attenuation quality factor that relates to the decay of the shear wave amplitude.

The results of the regression analysis using the functional form of equation (18), for each macroseismic intensity level are shown in Table 2. Equations (19), (20), (21) and (22) provide a way of converting the values in Table 1 into those given in Table 3 for $n$ ', $m$ ' and $c^{\prime}$ so that they can be compared directly with the values in Table 2 .

\begin{tabular}{cccc}
\hline $\begin{array}{c}\text { Intensity } \\
\text { level }\end{array}$ & $n$ & $m$ & $c$ \\
\hline 2 & 0.3254 & 0.0028 & 2.4986 \\
3 & 0.5646 & 0.0023 & 1.9096 \\
4 & 0.6464 & 0.0028 & 1.7109 \\
5 & 0.3934 & 0.0047 & 3.1691 \\
6 & 0.6690 & 0.0035 & 3.2245 \\
7 & 0.3882 & 0.0068 & 4.6988 \\
8 & 0.2503 & 0.0148 & 5.4749 \\
\hline
\end{tabular}

Table 2. Coefficients in equation (18) from regressions

The curves for each macroseismic intensity level II to VIII is shown plotted in Figure 4. The equations are plotted in alternative form to that presented in Johnston's paper to aid 
comparison with the results from Ambraseys analyses which are presented in Section 6.2. The curves are plotted with the log of the felt area against the moment magnitude. To derive the moment magnitude for an event where $n$ isoseismals are known Johnston simply derives the average value from the moment magnitudes of all the contributing intensity levels as shown in equation (23)

$$
M_{W}=\frac{1}{n} \sum_{i=1}^{n} M_{W}^{i}
$$

where $i$ only includes cases where there are felt areas. $M_{w}$ represents the best estimate of the moment magnitude of the event.

Figure 5 shows the results of processing Johnston's data through equations (18) and (23), the figure compares the magnitude values in the original data with the magnitude produced by the same data processed through the equations. If the equations produced ideal results then the plotted points would all lie on the diagonal solid line which is a line with slope 1.0 which passes through the origin, however clearly they do not. The dashed line shows the results of a

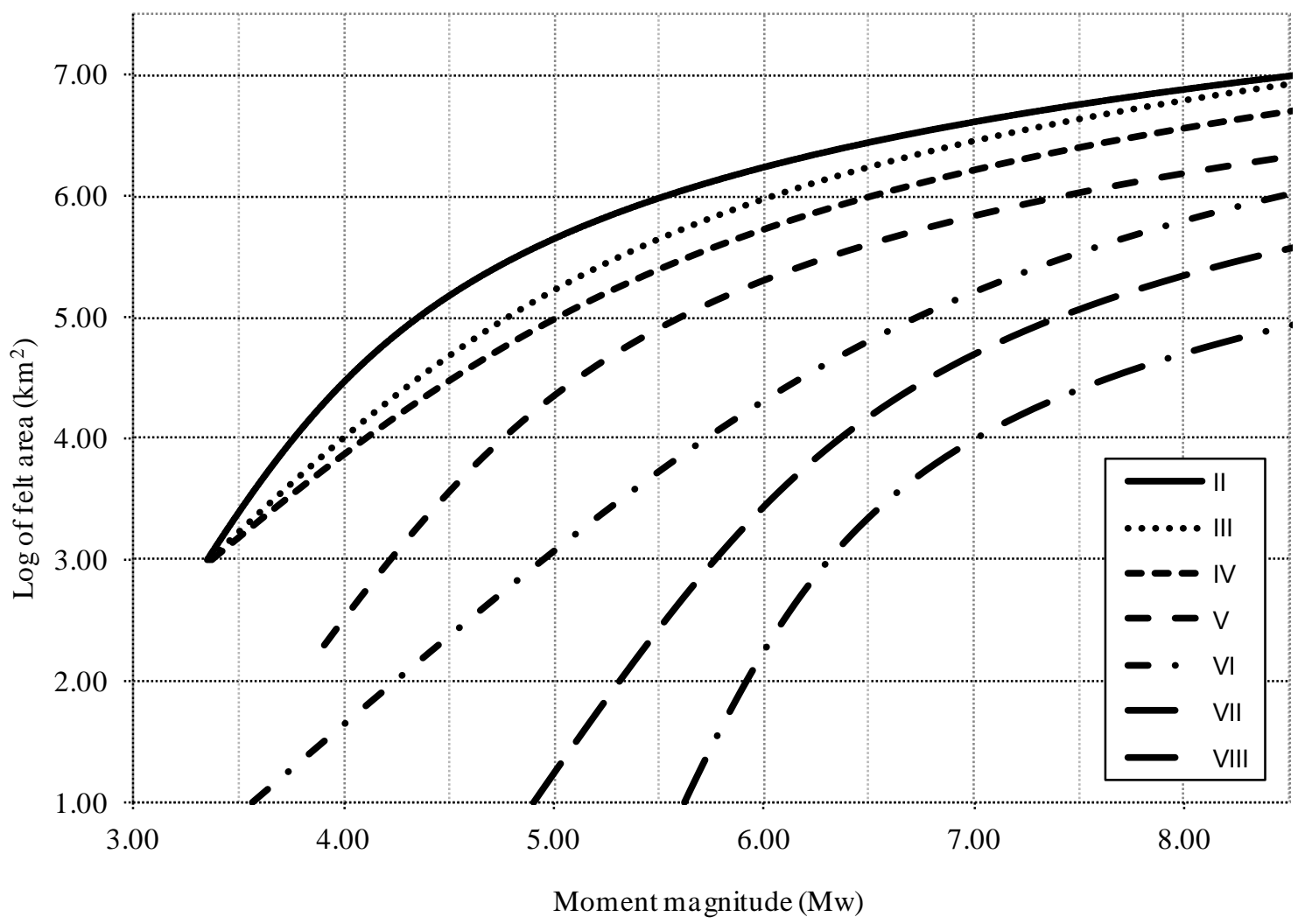

Figure 4. Analysis of Johnston's Moment Magnitude data using equation (18)

linear regression performed on the data and its position relative to the dotted line is an indicator of how well the equations reproduce the original data. It can be seen that the equations over estimate the moment magnitudes less than 6.0 and under estimate those greater than 6.0. The distance between the regression line and the diagonal line gives a measure of the 


\begin{tabular}{cccc}
\hline $\begin{array}{c}\text { Intensity } \\
\text { level }\end{array}$ & $n^{\prime}$ & $m^{\prime}$ & $c^{\prime}$ \\
\hline 2 & 0.64 & 0.0017 & 1.164 \\
3 & 0.68 & 0.0019 & 1.370 \\
4 & 0.65 & 0.0026 & 1.700 \\
5 & 0.53 & 0.0035 & 2.790 \\
6 & 0.69 & 0.0024 & 3.136 \\
7 & 0.37 & 0.0045 & 4.972 \\
8 & 0.29 & 0.0079 & 5.486 \\
\hline
\end{tabular}

Table 3. Coefficients converted from Table 1 to an equivalent form to those in Table 2

accuracy of the equations at a given moment magnitude. The equation for the regression line is given by equation (24)

$$
M=0.997+0.823 m
$$

where $M$ is the derived $\mathrm{M}_{\mathrm{w}}$ and $m$ is the original $\mathrm{M}_{\mathrm{w}}$ from the dataset.

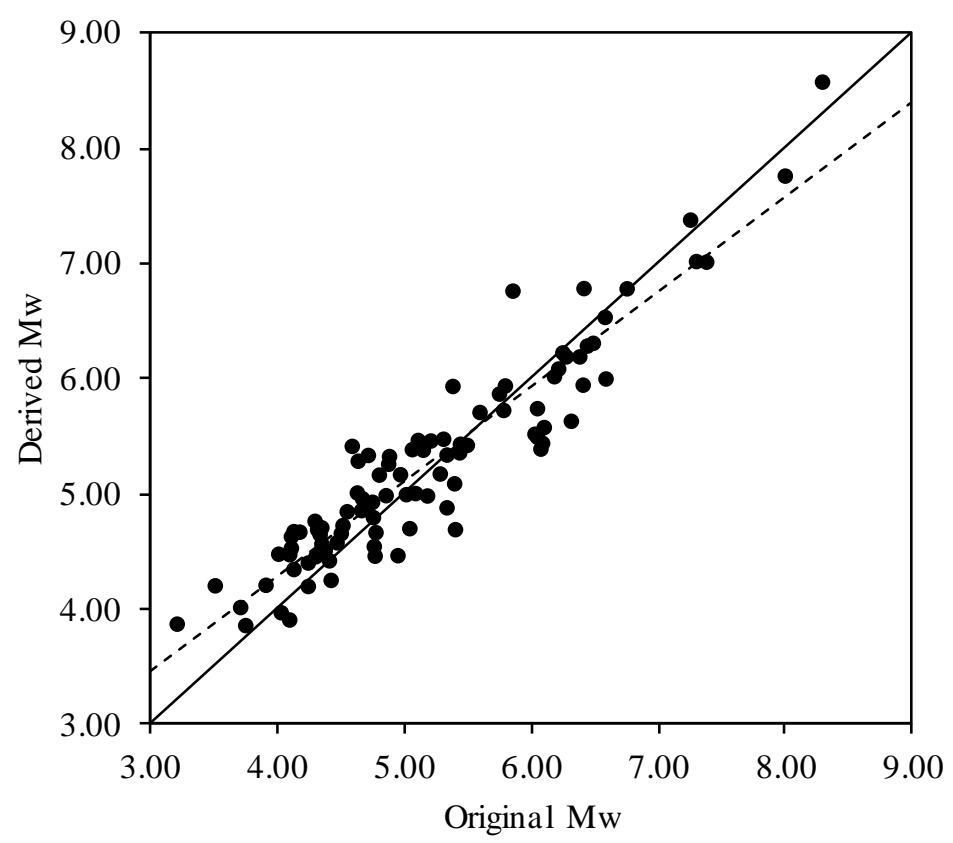

Figure 5. Plot showing the scatter in the results from the Johnston based data through equations (18) and (23). Dashed line is the regression equation which is compared with the solid line which represents a perfect reproduction by the equations (18) and (23)

\subsection{Ambraseys method - simultaneous regression across all intensity levels}

In a similar manner to the previous section, Johnston's dataset is analysed using the approach in Ambraseys [2]. Ambraseys studied NWE, which is part of the European SCR and considered events with surface wave magnitudes of 4.0 to 5.8 .

Ambraseys adopted a regression method that simultaneously considers all intensity levels and then derives the magnitude by averaging the contribution from each intensity level. Ambraseys equation from the regression on NWE data is given by equation (25) 


$$
M_{S}=-1.10+0.62 I+0.0013 D+1.62 \log (D)
$$

where $M_{s}$ is the surface wave magnitude $I$ is the intensity level of the isoseismal with effective radii of felt areas $D$. To find the magnitude for an event with more than one isoseismal equation (25) is generalised to give the average value for the sum of the isoseismals which results in equation (26)

$$
M_{S}=-1.10+0.62 j^{-1} \sum_{i}^{j} I_{i}+0.0013 j^{-1} \sum_{i}^{j} D_{i}+1.62 j^{-1} \sum_{i}^{j} \log \left(D_{i}\right)
$$

here $j$ is the number of isoseismals available for an event and $I_{i}$ is the numeric values of the macroseismic intensity levels and $D_{i}$ is the radii of felt area of isoseismal $i$.

Applying Ambraseys method to Johnston's data using a method of minimisation of the least squares which incorporates a Levenberg-Marquardt non-linear convergence routine results in equation (27) which is in terms of moment magnitude

$$
M_{w}=-0.796+0.58 I+3.462 .10^{-7} D+0.746 \log (D)
$$

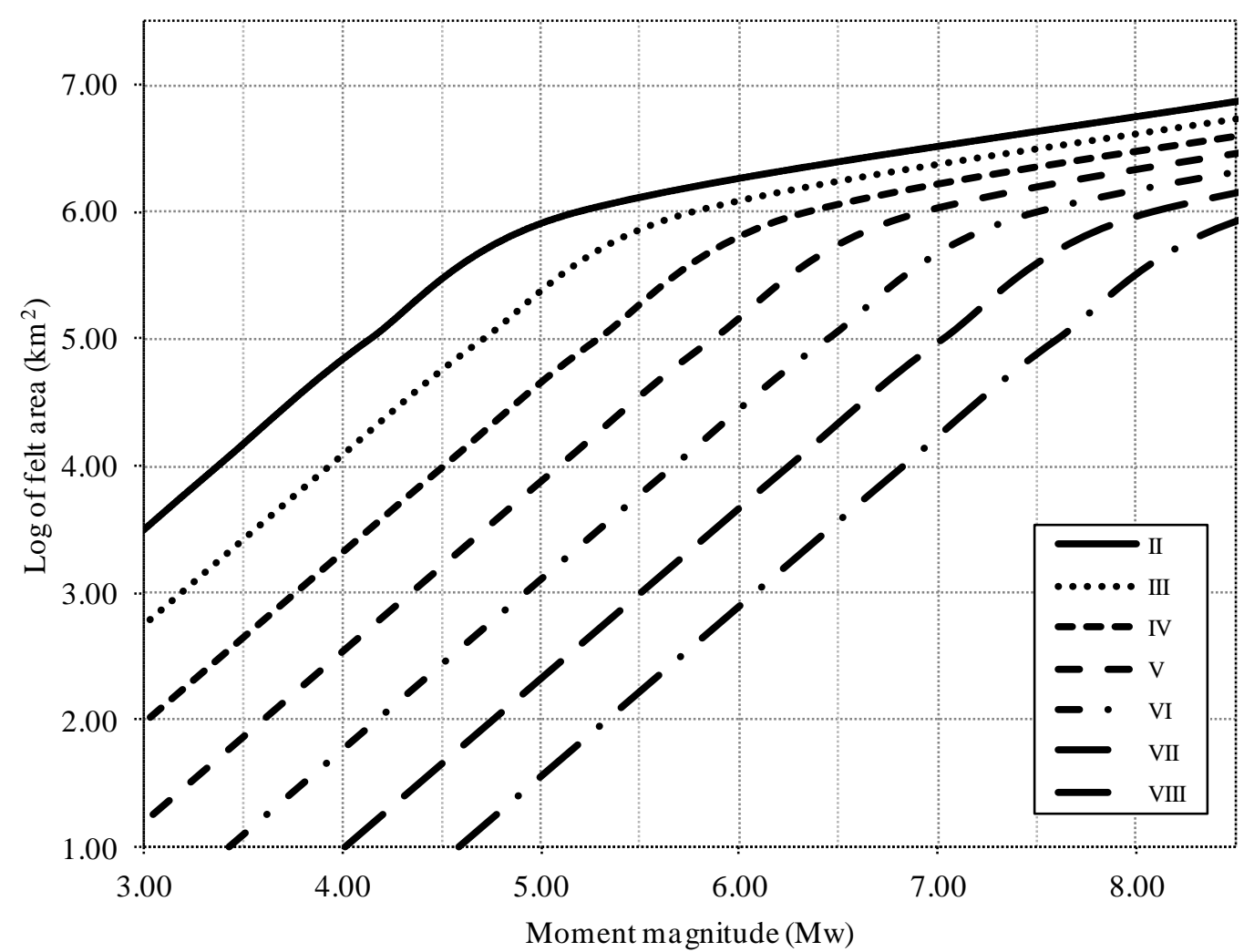

Figure 6. Analysis of Johnston's Moment Magnitude data using Ambraseys' approach of simultaneous regression over all intensity levels using equation (28)

It can be seen that the first two terms in equation (27) become a combined constant for each specific intensity level but that the third and four terms do not, unlike the terms in equation (18). Figure 6 shows a plot of equation (27).

Introducing the averaging process over the number of isoseismals available produces equation (28) 


$$
M_{w}=-0.796+0.58 j^{-1} \sum_{i}^{j} I_{i}+3.462 \times 10^{-7} j^{-1} \sum_{i}^{j} D_{i}+0.76 j^{-1} \sum_{i}^{j} \log \left(D_{i}\right)
$$

in the same way as for equation (26).

Figure 7 shows the results of processing Johnston's data through equations (27) and (28) the figure compares the magnitude values in the original data with the magnitude produced by the same data processed through the equations. As in Section 6.1 if the equations produced ideal results then they would all line on the diagonal dotted line however as in the case of Johnston's method they do not. Consistent with Section 6.1, the dashed line shows the results of a linear regression performed on the data and its position relative to the solid line is an indicator of how well the equations reproduce the original data. It can be seen that the equations over estimate the moment magnitudes that are less than 5.3 and under estimates those greater than 5.3. The equation for the regression line is given by equation (29)

$$
M=1.252+0.776 m
$$

where $M$ is the derived $\mathrm{Mw}$ and $m$ is the original $\mathrm{Mw}$ from the dataset. Comparing this with equation (18) it can be seen that the Ambraseys method does not reproduce the results as well as Johnston's method.

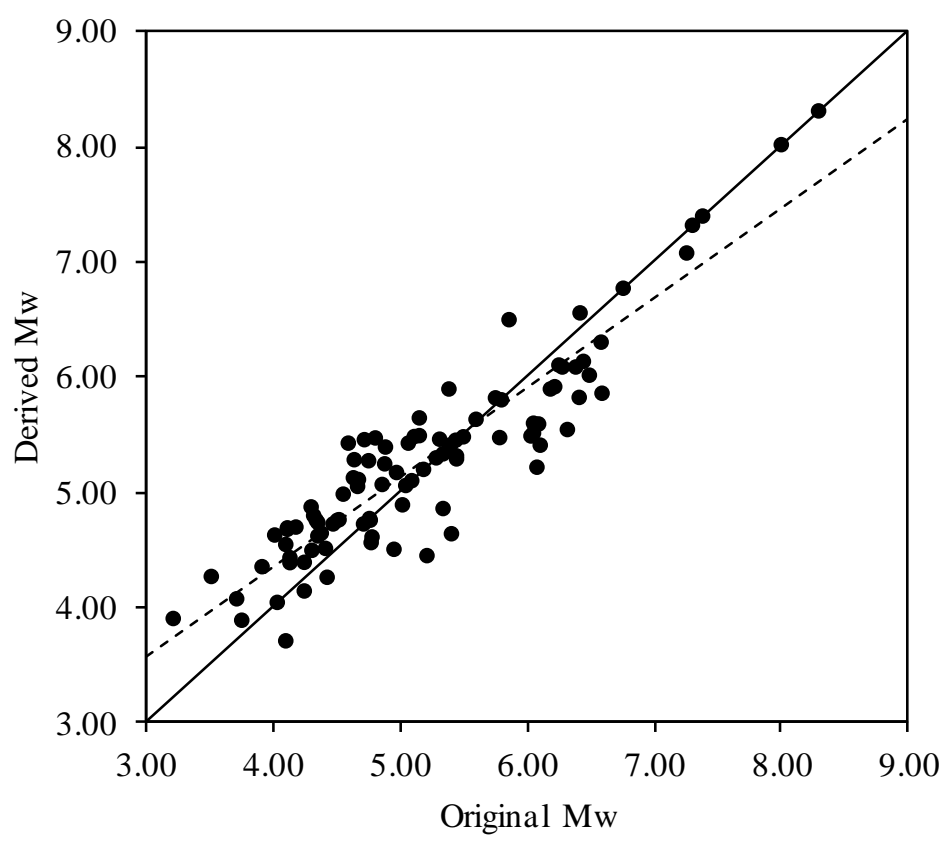

Figure 7. Plot showing the scatter in the results from Ambraseys regression on the Johnston based data through equations (28). Dashed line is the regression equation which is compared with the solid line which represents a perfect reproduction by equations (28)

\section{THE ATTENUATION FUNCTION}

The analysis by Frankel [6] only considered macroseismic intensity level II in the context of the felt area; it is however possible to apply the same form of analysis to other macroseismic intensity levels and that extension is described in this section and is similar to the approach used by Johnston [3].

Murphy and O'Brien's equation (11) correlates the peak ground acceleration $a$ with macroseismic intensity $I$ and shows that increases in peak ground acceleration are correlated 
with increasing intensity. As that study was based on the peak ground acceleration, it made the implicit assumption that each of the macroseismic intensity levels is associated with a zero period amplitude (zpa), in other words, the intensity indicators behave as rigid bodies. Inspection of the intensity indicators in the MMI scale used by Murphy and O'Brien clearly show that they are all dynamic systems of one form or another that vibrate and have natural frequencies that are much lower than the frequency of $33 \mathrm{~Hz}$, which is commonly taken to be the typical natural frequency for systems that effectively behave as rigid bodies under seismic input motions. This suggests that macroseismic intensities are functions of their natural or characteristic frequencies and that the correlation should therefore be with the spectral ground acceleration rather than the peak ground acceleration.

The idea that intensities are more closely related to the spectral ground acceleration as opposed to the peak ground acceleration was considered in detail by Brazee [13] with a further study being undertaken by O'Brien [14] although neither study could arrive at specific values. Based on Frankel [6], Johnston [3] used these studies as guides and took intensities II

\begin{tabular}{ccl}
\hline $\begin{array}{c}\text { Intensity } \\
(\mathrm{MMI})\end{array}$ & $\begin{array}{c}\text { Mean } \\
\text { Frequency } \\
(\mathrm{Hz})\end{array}$ & \multicolumn{1}{c}{ Prime intensity indicator } \\
\hline 2 & 1.0 & people at rest on upper floors of houses \\
3 & 1.1 & Hanging objects \\
4 & 1.5 & Cars rocking \\
5 & 1.8 & Small objects move or turn \\
6 & 2.5 & Everyone feels movement \\
7 & 4.0 & Car drivers feel shaking \\
8 & 5.0 & Even heavy furniture moves and partly overturns \\
\hline
\end{tabular}

Table 4. The characteristic frequency range associated with intensity levels II to VIII

to VI as having a response frequency of $3 \mathrm{~Hz}$ as they are associated with the response of the human body. Although in Frankel [6], the frequency finally used for the felt area, intensity II, is $4.2 \mathrm{~Hz}$ on the assumption that the corner frequency is the relevant frequency. It was noted in [9], that the magnitude of the Fourier acceleration for intensity II agrees with that determined by Frankel [6] but the frequency at which it occurs is much lower than that determined by Frankel. This is because Frankel assumed that intensity level II would correspond to the acceleration plateau, which is defined by the corner frequency, whereas the approach used here uses intensities that are spread across a range of frequencies between 1.0 to $5.0 \mathrm{~Hz}$.

\begin{tabular}{cccc}
\hline $\begin{array}{c}\text { Intensity } \\
\text { level }\end{array}$ & $0.66(\mathrm{f} / \mathrm{Q})$ & $\mathrm{f}$ & $\mathrm{Q}$ \\
\hline 2 & 0.00126 & 3 & 1571 \\
3 & 0.00139 & 3 & 1424 \\
4 & 0.00194 & 3 & 1020 \\
5 & 0.00260 & 3 & 761 \\
6 & 0.00176 & 3 & 1125 \\
7 & 0.00328 & 5 & 1006 \\
8 & 0.00586 & 5 & 563 \\
\hline
\end{tabular}

Table 5. The values for $Q$ for SCR taken from the results in Johnston [3] 
For intensities VII to VIII Johnston noted that they are associated with the response of structures and used a response frequency of $5 \mathrm{~Hz}$ based on the paper by Nuttli and Herrmann [15]. In their paper Nuttli and Herrmann do not actually make such a statement but note that peak acceleration usually occurs at approximately $5 \mathrm{~Hz}$. Johnston notes that some structures could have natural frequencies that may be higher or lower than $5 \mathrm{~Hz}$, depending on their stiffness. The subject of the frequencies of intensity indicators has been explored by Belsham [9] using the dynamic characteristics of selected intensity indicators for levels II to VIII. The studies revealed that, within this range of intensities, the natural frequency of the indicators increase with increasing level of intensity and this has enabled a refinement of Johnston's analysis of $Q$, the results from [9] are summarised in Table 4.

\begin{tabular}{clcc}
\hline $\begin{array}{c}\text { Intensity } \\
\text { level }\end{array}$ & $0.898(\mathrm{f} / \mathrm{Q})$ & $\mathrm{f}$ & $\mathrm{Q}$ \\
\hline 2 & 0.0028 & 1.0 & 320 \\
3 & 0.0023 & 1.1 & 430 \\
4 & 0.0028 & 1.5 & 481 \\
5 & 0.0047 & 1.8 & 346 \\
6 & 0.0035 & 2.5 & 606 \\
7 & 0.0068 & 4.0 & 528 \\
8 & 0.0148 & 5.0 & 303 \\
\hline
\end{tabular}

Table 6. The values for $Q$ for SCRs from the results from this study

Johnston [3] calculates the values for $Q$ from the second term in equation (18), which reduces to $0.66(f / Q)$ and equates this term to the coefficient that results from the regression analysis for each intensity level. The results are reproduced in Table 5 where the effect of the assumptions made on the frequencies that correspond to the intensity levels become clear.

The analysis is repeated in this study using the frequencies from Table 4 in conjunction with the coefficients in Table 2, which correspond to the revised analysis in this study. The results are given in Table 6 where it can be seen the value of $Q$ is fairly constant at an average of 430 across the frequency range 1 to $5 \mathrm{~Hz}$.

\section{DISCUSSION}

In this article the use of macroseismic intensity to determine the moment magnitudes of earthquakes is discussed in terms of the datasets and the statistical methods used to analyse the data. The relationship between the underlying equations is explored and is extended to show that the point source model provides a theoretical physical basis for the functional forms of the statistically derived equations.

The dataset used in this study is a condensed version of the SCR data given in Johnston [3]. The data has been used in the analyses of both Johnston's approach and the approach in Ambraseys [2] using functional forms of the equations from each method configured to provide a common output presentation format that allows a direct comparison.

The equations of Johnston and Ambraseys have been assessed for their ability to derive consistent values for the magnitudes of earthquakes from the isoseismal felt areas by comparing the calculated data against the original magnitude data for each event in the dataset. This process revealed that both Johnston's method and Ambraseys method overestimate low magnitude events and underestimate the higher magnitude events which 
introduces uncertainty in the derived magnitudes. The consistency of these processes can be improved and the uncertainty reduced by introducing weighing functions.

The functional forms of the equations underlying the statistical methods used by Johnston's and Ambraseys to derive the magnitudes from the macroseismic data are found to differ by the Murphy and O'Brien [7] simple two parameter equation, equation (11). This should inform in developing future analysis of isoseismal data.

The results from applying the modified Johnston's equations have been used in conjunction with macroseismic intensity characteristic frequencies derived in Belsham [9], to refine Johnston's model in terms of determining the shear wave attenuation quality factor $Q$.

An important consideration when comparing the methods of Johnston and Ambraseys is that Johnston's method allows for independent coefficients for each intensity level whilst the Ambraseys approach constrains the coefficient to one representative value. As discussed above, this study has highlighted the significance of the attenuation function and that the quality factor should be a constant, at least for SCRs. In the Ambraseys' approach the attenuation term is almost negligible due to the very small value for $c_{3}$. In addition, this study has shown that Johnston's approach aligns with theoretical source models. These are strong reasons for giving preference to Johnston's methodology.

\section{CONCLUSIONS}

For regions with low seismic activity, which in most cases are SCRs, the determination of the magnitudes of historical events is an important consideration. Approaches have been developed by both Johnston and Ambraseys, and others, to derive historic magnitudes using events for which both instrumented magnitudes and macroseismic data is available. The approaches of Johnston [3] and Ambraseys [2] differ in their methodology, both in terms of the functional form used to model the attenuation and the method used for the regression analysis. This study has shown that the approach used by Johnston gives the closer estimate of the magnitude of a historical event for the general SCR.

Johnston used a functional form of attenuation equation developed by Frankel [6], whereas Ambraseys developed a functional form of attenuation equation based on the Köveslighethy equation. As these equations are representing the same physical process they should be closely related and this study has shown that to be the case. Additionally, they are also shown to be forms of a point source model. The similarity between the equation from Murphy and O'Brien and the Köveslighethy equation is also noted.

Based on Frankel [6], Johnston associated a response frequency of $3.0 \mathrm{~Hz}$ with macroseismic intensities II to VI and $5.0 \mathrm{~Hz}$ for macroseismic intensities V to VIII. Through dynamic analysis of key intensity indicators Belsham [9] has determined characteristic frequencies associated with each macroseismic intensity level these have been used in this study as a refinement in Johnston's approach. The inclusion of those frequencies points towards an almost constant quality factor across the frequency range 1 to $5 \mathrm{~Hz}$. This suggests that the quality factor for shear waves in SCRs is only weakly frequency dependent.

The findings from this study should help improve the determination of the moment magnitude of historic events when using an events collected intensity records. In addition, the explanation of the interrelationships between various approaches for determining the seismic moment and the determination of key seismic parameters should also help in improving the calibration of seismic source models for both instrumented and historic events. This is possible by relating the accelerations at the surface of a homogenous half-space to an intensity level through the relationship between Johnston's method and point source theory such as used in the Stochastic Method. 


\section{REFERENCES}

[1] Report: Macroseismic estimation of earthquake parameters, NEtwork of Research Infrastructures for European Seismology, 2007.

[2] Ambraseys N. N., (1985), Intensity-attenuation and Magnitude-Intensity relationships for Northwest European Earthquakes, Earthquake Engineering and Structural Dynamics, 13, pp. 733 - 778.

[3] Johnston A. C., (1996), Seismic moment assessment of earthquakes in stable continental regions - II Historical Seismicity, Geophys. J. Int. 124, pp. 381 - 414.

[4] Johnston A. C., (1989), The Seismicity of 'Stable Continental Interiors', Earthquakes at North Atlantic Passive Margins: Neotectonics and Postglacial Rebound, pp. 299 - 327, Kluwer Academic Publishers.

[5] Boore D. M., (1983), Stochastic simulation of high-frequency ground motions based on seismological models of the radiated spectra, Bulletin of the Seismological Society of America, 73, pp. 1865 - 1894.

[6] Frankel A., (1994), Implications of Felt Area-Magnitude Relations for Earthquake Scaling and the Average Frequency of Perceptible Ground Motion, Bulletin of the Seismological Society of America, 84, 2, pp. 462 - 465.

[7] Murphy J. R. and O'Brien L. J., (1977), The correlation of peak ground acceleration amplitude with seismic intensity and other physical parameters, Bulletin of the Seismological Society of America, 67, pp. 877 - 915.

[8] Köveslighethy R. von, (1907), Seismicher Starkegrad und intensitat der Beben, Gerlands Beitr.z. Geophysik, 1907, vol. 8, pp. $363-366$.

[9] Belsham C. S., (2008), The Dynamic Response of Seismic Intensity Indicators, Proceedings of the Ninth International Conference on Computational Structures Technology, Athens, Greece.

[10] Hanks and Kanamori (1979), A Moment Magnitude Scale, J. Geophys. Res. 84, pp. $2348-2350$.

[11] Boore D. M., (2003), Simulation of Ground Motion Using the Stochastic Method, Pure and Applied Geophysics 160: pp. 635 - 676.

[12] Ambrasesys N. N. and Douglas J., (2004), Magnitude calibration of north Indian earthquakes, Geophys. J. Int., 159, pp. 165 - 206.

[13] Brazee R. J., (1979), Reevaluation of the Modified Mercalli Intensity Scale for Earthquakes using Distance as Determinant, Bulletin of the Seismological Society of America, 69, p. 911.

[14] O'Brien L. J., (1980), The correlation of response spectral amplitudes with seismic intensity, NUREG/CR-1259, R6, RA; United States Nuclear Regulatory Commission; Division of Reactor Safety Research. Washington, DC.

[15] Nuttli, O.W. \& Herrmann, R.B., (1984), Ground motion of Mississippi Valley earthquakes, J. tech. Topics civ. Eng., 110, pp.54 - 69. 
APPENDIX A

\begin{tabular}{|c|c|c|c|c|c|c|c|c|c|}
\hline Ref & $\log \mathrm{M}_{0}$ & $\mathrm{M}_{\mathrm{W}}$ & $\mathrm{r}_{\mathrm{II}}$ & $\mathrm{r}_{\mathrm{III}}$ & $\mathrm{r}_{\mathrm{IV}}$ & $\mathrm{r}_{\mathrm{V}}$ & $\mathrm{r}_{\mathrm{VI}}$ & $\mathrm{r}_{\mathrm{VII}}$ & $\mathrm{r}_{\mathrm{VIII}}$ \\
\hline NA-25-0301 & 25.70 & 6.47 & 6.42 & 6.15 & 5.84 & 5.16 & 4.81 & 4.01 & 3.27 \\
\hline NA-29-0812 & 23.35 & 4.90 & 5.95 & & 5.24 & 3.94 & 3.08 & 3.20 & \\
\hline NA-29-1118 & 26.92 & 7.28 & 6.74 & 6.64 & 6.38 & 5.94 & 5.43 & & \\
\hline NA-35-1101 & 25.36 & 6.24 & 6.33 & 6.17 & 5.89 & 5.11 & 4.60 & 2.88 & \\
\hline NA-39-1019 & 24.00 & 5.33 & 6.18 & 5.76 & 5.20 & 4.51 & 3.75 & & \\
\hline NA-40-1220 & 24.20 & 5.47 & 5.62 & 5.79 & 5.24 & 4.56 & 3.85 & 2.61 & \\
\hline NA-44-0905 & 24.73 & 5.82 & 6.06 & 5.91 & 5.55 & 5.04 & 4.32 & 3.76 & 3.03 \\
\hline NA-62-0202 & 22.40 & 4.27 & 4.94 & & & 3.60 & 2.21 & & \\
\hline NA-63-0303 & 23.04 & 4.69 & 5.38 & & 4.81 & 4.45 & 3.71 & & \\
\hline NA-65-1021 & 22.98 & 4.65 & 5.55 & & 5.08 & 4.13 & 3.60 & & \\
\hline NA-66-0101 & 22.40 & 4.27 & 4.67 & & & 3.13 & & & \\
\hline NA-67-0604 & 22.49 & 4.33 & 4.75 & & & 3.99 & & & \\
\hline NA-67-0613 & 22.18 & 4.12 & 3.85 & & & 2.81 & & & \\
\hline NA-68-1109 & 24.11 & 5.41 & 6.19 & & 5.71 & 5.17 & 4.45 & 3.71 & \\
\hline NA-69-0101 & 22.56 & 4.37 & 4.92 & & & 4.14 & & & \\
\hline NA-69-1120 & 22.86 & 4.57 & 5.53 & 5.53 & 4.47 & 4.29 & & & \\
\hline NA-70-1117 & 22.20 & 4.13 & 4.99 & & & 4.25 & & & \\
\hline NA-72-0915 & 22.23 & 4.15 & 5.36 & & & & & & \\
\hline NA-73-0615 & 22.79 & 4.53 & 5.25 & 4.89 & 4.65 & 4.00 & & & \\
\hline NA-73-1130 & 22.18 & 4.12 & 4.98 & & 4.93 & 4.35 & 1.13 & & \\
\hline NA-74-0215 & 22.60 & 4.40 & 4.83 & & 4.68 & 3.80 & & & \\
\hline NA-75-0613 & 21.66 & 3.77 & 4.23 & & 3.68 & & & & \\
\hline NA-75-0709 & 22.51 & 4.34 & 4.91 & & 4.70 & 4.28 & 2.87 & & \\
\hline NA-75-0712 & 22.23 & 4.15 & 5.15 & 4.82 & 3.82 & & & & \\
\hline NA-76-0325 & 22.99 & 4.66 & 5.45 & & & 4.98 & 3.77 & & \\
\hline NA-78-0218 & 21.90 & 3.93 & & 4.71 & 3.86 & 2.82 & & & \\
\hline NA-78-0616 & 22.81 & 4.54 & 5.45 & & & 3.90 & & & \\
\hline NA-79-0819 & 23.18 & 4.79 & & 4.75 & 4.44 & 3.81 & & & \\
\hline NA-80-0727 & 23.63 & 5.09 & 5.82 & & 5.46 & 4.71 & 4.06 & 2.60 & \\
\hline NA-82-0109a & 24.28 & 5.52 & & 5.71 & 5.36 & 4.89 & 3.38 & & \\
\hline NA-82-0109b & 23.19 & 4.79 & 5.14 & 4.90 & 4.05 & 3.70 & & & \\
\hline NA-82-0111 & 23.67 & 5.11 & 5.42 & & 4.91 & 4.50 & 3.45 & & \\
\hline NA-82-0119 & 22.56 & 4.37 & 5.13 & & & 4.22 & 2.76 & & \\
\hline NA-82-0121 & 22.67 & 4.45 & & 4.54 & & 2.81 & & & \\
\hline NA-82-0331 & 22.20 & 4.13 & 4.96 & & 4.58 & 3.90 & & & \\
\hline NA-82-0402 & 21.60 & 3.73 & 4.50 & & 3.90 & & & & \\
\hline NA-82-0616 & 22.05 & 4.03 & 4.85 & & 4.50 & 3.90 & & & \\
\hline NA-82-0713 & 20.85 & 3.23 & 4.25 & & 3.70 & & & & \\
\hline NA-82-0813 & 21.30 & 3.53 & 4.66 & & 4.25 & & & & \\
\hline NA-83-1007 & 23.36 & 4.91 & 5.81 & & 5.52 & 4.79 & 3.42 & & \\
\hline NA-84-0908 & 23.46 & 4.97 & 4.83 & & & 3.93 & & & \\
\hline NA-86-0131 & 23.32 & 4.88 & 5.52 & & 5.10 & 4.41 & 3.02 & & \\
\hline NA-86-0712 & 22.65 & 4.43 & 5.01 & & 4.24 & 3.51 & 2.48 & & \\
\hline NA-87-0610 & 23.49 & 4.99 & 5.68 & & & 4.80 & 3.20 & & \\
\hline
\end{tabular}




\begin{tabular}{|c|c|c|c|c|c|c|c|c|c|}
\hline Ref & $\log \mathrm{M}_{0}$ & $\mathrm{M}_{\mathrm{W}}$ & $\mathrm{r}_{\text {II }}$ & $\mathrm{r}_{\text {III }}$ & $\mathrm{r}_{\mathrm{IV}}$ & $r_{V}$ & $\mathrm{r}_{\mathrm{VI}}$ & $\mathrm{r}_{\mathrm{VII}}$ & $\mathrm{r}_{\mathrm{VIII}}$ \\
\hline NA-88-1125 & 24.82 & 5.88 & 6.52 & & 6.16 & 5.68 & 5.12 & & \\
\hline NA-89-1225b & 25.11 & 6.07 & 5.90 & & 5.55 & 4.85 & & & \\
\hline NA-90-0926 & 22.48 & 4.32 & 5.16 & & 4.71 & 4.13 & 3.13 & & \\
\hline NA-90-1019 & 22.92 & 4.61 & 5.81 & & 5.74 & 4.40 & & & \\
\hline NA-91-0504 & 22.54 & 4.36 & 4.96 & & 4.56 & 4.06 & 2.97 & & \\
\hline NA-94-0116 & 22.08 & 4.05 & & 4.09 & 3.52 & 2.69 & 1.70 & & \\
\hline AF-39-0622 & 25.77 & 6.51 & 6.32 & & 6.03 & 5.78 & 4.87 & 2.80 & 2.43 \\
\hline AF-45-0912 & 25.15 & 6.10 & & 5.57 & & & & & \\
\hline AF-55-0912 & 25.66 & 6.44 & & & 5.89 & 5.68 & 5.20 & 4.92 & \\
\hline AF-69-0929 & 25.65 & 6.43 & 6.30 & 5.88 & 5.61 & 5.04 & 4.30 & 3.37 & 2.98 \\
\hline AF-83-1222 & 25.41 & 6.27 & & 6.12 & & 5.45 & & & \\
\hline AU-66-0503 & 22.74 & 4.49 & & 5.01 & 4.67 & 3.16 & & & \\
\hline AU-68-1014 & 25.92 & 6.61 & & 6.12 & 5.81 & 5.18 & 4.24 & 3.09 & 2.53 \\
\hline AU-73-0309 & 23.76 & 5.17 & & & 5.48 & 4.66 & & & \\
\hline AU-79-0602 & 25.19 & 6.13 & 6.03 & & 5.66 & 4.69 & 3.53 & 2.41 & 2.06 \\
\hline AU-82-1121 & 23.03 & 4.69 & & 5.15 & 4.82 & 4.15 & & & \\
\hline AU-88-0122a & 25.45 & 6.30 & & 6.24 & 5.87 & 5.43 & 4.21 & 3.74 & \\
\hline AU-88-0122b & 25.61 & 6.41 & & 6.24 & 5.87 & 5.43 & 4.21 & 3.74 & \\
\hline AU-88-0122c & 25.91 & 6.61 & 6.44 & & 6.11 & 5.76 & 4.46 & & \\
\hline CH-62-0318 & 25.11 & 6.07 & & & 5.61 & 5.10 & 4.11 & 2.85 & 1.69 \\
\hline CH-69-0725 & 24.71 & 5.81 & & & & & 3.60 & 3.03 & 2.30 \\
\hline CH-69-1217 & 23.24 & 4.83 & & & 4.99 & 4.77 & & & \\
\hline CH-69-1220 & 23.16 & 4.77 & & & 4.79 & 4.47 & & & \\
\hline СH-74-0422 & 24.04 & 5.36 & & 5.20 & 4.76 & 3.54 & 2.96 & 1.97 & \\
\hline CH-79-0709 & 24.20 & 5.47 & & 5.60 & 5.22 & 4.80 & 3.38 & 2.60 & 1.48 \\
\hline CH-84-0512 & 25.17 & 6.11 & & & 5.32 & 4.84 & 3.78 & & \\
\hline CH-87-0802 & 23.56 & 5.04 & & & & 3.99 & 3.10 & 1.82 & \\
\hline EU-78-0903 & 23.70 & 5.13 & & 5.56 & 5.23 & 4.79 & 3.75 & 3.11 & \\
\hline EU-83-1108 & 23.20 & 4.80 & 5.17 & 5.11 & 4.26 & 3.35 & 2.59 & 1.96 & \\
\hline EU-86-0205 & 23.11 & 4.74 & & 5.52 & 5.25 & 4.82 & & & \\
\hline EU-88-0808 & 24.43 & 5.62 & & 5.81 & 5.55 & & & & \\
\hline EU-89-0123 & 23.76 & 5.17 & & 5.58 & 5.29 & 4.83 & & & \\
\hline EU-92-0413 & 24.04 & 5.36 & 5.88 & 5.54 & 5.16 & 4.58 & 3.82 & 2.81 & \\
\hline IN-56-0721 & 25.08 & 6.05 & 5.91 & 5.41 & 5.01 & 4.51 & 3.73 & 3.55 & 3.17 \\
\hline IN-67-1210 & 25.51 & 6.34 & 6.19 & & 5.65 & 5.00 & 3.31 & 2.79 & \\
\hline IN-69-0413 & 24.66 & 5.77 & 6.20 & & 5.46 & 5.11 & 4.60 & & \\
\hline IN-70-0323 & 24.14 & 5.43 & 4.94 & 4.61 & 4.35 & 3.84 & 2.95 & 2.04 & \\
\hline IN-93-0929 & 25.31 & 6.21 & & 6.16 & 5.77 & 5.04 & 4.44 & 3.17 & 2.67 \\
\hline SA- $80-1120$ & 23.85 & 5.23 & 6.10 & & 5.18 & 4.66 & 3.51 & 3.12 & \\
\hline
\end{tabular}

Table A.1. Table is a condensed version of that given in Johnston [3] which details the events in global SCR which have information on both instrumentally measured magnitudes and isoseismals data

Notes for Table A.1.:

Ref is the same as given in Johnston [3]. $\log \mathrm{M}_{0}$ is the logarithm to the base 10 of the seismic moment measured instrumentally. $\mathrm{M}_{\mathrm{W}}$ is the moment magnitude. $\mathrm{r}_{\mathrm{i}}$ are the isoseismals radii where $i$ is the intensity level

In the refs column the prefixes are: NA - North America, AF - Africa, AU - Australia, CH - China, EU - Europe, IN - India, SA - South America 


\begin{tabular}{|c|c|c|c|c|c|c|c|c|c|}
\hline Ref & $\log \mathrm{M}_{0}$ & $\mathrm{M}_{\mathrm{W}}$ & $\mathrm{r}_{\mathrm{II}}$ & $\mathrm{r}_{\mathrm{III}}$ & $\mathrm{r}_{\mathrm{IV}}$ & $\mathrm{r}_{\mathrm{V}}$ & $\mathrm{r}_{\mathrm{VI}}$ & $\mathrm{r}_{\mathrm{VII}}$ & $\mathrm{r}_{\mathrm{VIII}}$ \\
\hline CH-18-0213 & 26.99 & 7.33 & 6.50 & & 6.36 & & 5.24 & 4.66 & 4.10 \\
AU-41-0429 & 26.17 & 6.78 & & 6.32 & 6.13 & 5.64 & 5.14 & 4.54 & 4.01 \\
CH-79-0521 & 23.6 & 5.07 & & & & 3.07 & 2.56 & 1.81 & \\
EU-84-0719 & 23.81 & 5.21 & & 5.38 & 5.02 & 3.94 & 3.14 & & \\
AU-87-1222 & 23.17 & 4.78 & 5.23 & & 4.83 & 4.15 & 3.04 & & \\
AU-89-0528 & 24.13 & 5.42 & 5.20 & & 4.89 & 4.39 & 3.56 & 2.81 & \\
AU-89-1227 & 24.19 & 5.46 & & 5.47 & 5.04 & 4.56 & 3.83 & 2.18 & 1.40 \\
EU-90-0402 & 23.10 & 4.73 & 5.38 & 5.13 & 4.79 & 4.16 & 3.20 & & \\
AU-92-0930 & 23.96 & 5.31 & 5.67 & 5.44 & 5.15 & 4.69 & & & \\
IN-34-0115 & 28.04 & 8.03 & 6.77 & & 6.53 & 6.31 & $5.40 *$ & $5.00 *$ & $4.70 *$ \\
SA-77-1123 & 27.11 & 7.41 & & 6.51 & 6.14 & 5.78 & 5.42 & & \\
AU-77-0819 & 28.48 & 8.32 & 7.10 & 6.91 & 6.64 & & & & \\
\hline
\end{tabular}

Table A.2. Table is a condensed version of that given in Johnston [3] which details the events occurring outside of SCR but for which there are isoseismals in the SCR, which have information on instrumentally measured magnitudes

Notes for Table A.2.:

Ref is the same as given in Johnston [3]. $\log \mathrm{M}_{0}$ is the logarithm to the base 10 of the seismic moment measured instrumentally. $\mathrm{M}_{\mathrm{W}}$ is the moment magnitude. $\mathrm{r}_{\mathrm{i}}$ are the isoseismals radii where $i$ is the intensity level

In the refs column the prefixes are: AU - Australia, CH - China, EU - Europe, IN - India, SA - South America Entries marked with an $*$ have the following average values in [3] - 6.08, 5.5, 5.03. 